\title{
Urban vulnerability and resilience within the context of climate change
}

\author{
E. Tromeur, R. Ménard, J.-B. Bailly, and C. Soulié \\ Egis Concept/Elioth, 4 rue Dolorès Ibarruri, 93188, Montreuil, France \\ Correspondence to: E. Tromeur (eric.tromeur@egis.fr)
}

Received: 22 November 2011 - Revised: 16 February 2012 - Accepted: 31 March 2012 - Published: 31 May 2012

\begin{abstract}
Natural hazards, due to climate change, are particularly damaging in urban areas because of interdependencies of their networks. So, urban resilience has to face up to climate risks. The most impacting phenomenon is the urban heat island (UHI) effect. The storage capacity of heat is depending on shapes of buildings, public spaces, spatial organization, transport or even industrial activities. So, adaptive strategies for improving urban climate could be possible in different ways. In the framework of the French project Resilis, this study characterises urban vulnerability and resilience in terms of energy needs of buildings and outside urban comfort according to the IPCC carbon dioxide emission scenarios B2 and A2 for the period 2050-2100 for 10 French cities. The evolutions of four climate indicators in terms of heating and cooling needs and number of hours when the temperature is above $28^{\circ} \mathrm{C}$ are then obtained for each city to analyse climate risks and their impacts in urban environment.
\end{abstract}

\section{Introduction}

Urban society is more and more complex: new sets of social relations, high degrees of connectivity and competitiveness objectives. If urbanity is made of resources accumulation, power concentration, territorial attractiveness and cultural life; it is also a new vector of risk, particularly due to concentration issue. External hazards, especially those due to climate change, become more significant when occurring in an urban environment: hazards are often magnified by urbanity. Meanwhile, risks and damages are less and less accepted by populations and economic activities. When cities are supposed to embody security and development, the latest events (heat waves, Xynthia) have highlighted their weaknesses and questioned the way risks are anticipated and man- aged. Today's policies in risk management and assessment usually focus on a single risk, though the urban context induces domino effects and can spread damages. Indeed, interdependencies between organisations, infrastructures and activities are strong in urban areas. Unfortunately, policies are mainly focused on crisis management, whereas prevention measures are needed prior to the crisis and recovery plans have to be considered before the event occurs. Thus, risk management cannot be tackled without a global approach.

These facts have led local authorities to the expression of new needs to improve city resilience. Defined as the ability of a city to absorb disturbance and recover its functions after a disturbance (Lhomme et al., 2010), urban resilience has become a new paradigm in risk management methods enabling to tackle the challenges identified above. Resilis project aims precisely at the development of those innovative solutions dedicated to improving urban resilience. The main outcome is the development of methods and tools addressed to local authorities, networks operators, populations and all stakeholders. On the long term, the objective is to develop tools to prepare, adapt and conceive technical and social systems so they are able to cope with, absorb and recover from disturbances.

The weather conditions can be a stress factor for buildings and infrastructures. They are usually adapted to the climate they are built in (e.g., traditional housing in warm countries), but modifications of climate standards can affect the comfort of both external and internal living places. Urban climate is a complex system, which is different from one city to another. The most impacting phenomenon is the urban heat island (UHI) effect. This effect characterises an urban sector where air and surface temperatures are superior to the ones in rural suburb. This phenomenon appears in big cities and is mainly felt during the night when heating trapped during the 
day is released in the atmosphere. The storage capacity of heat is depending on shapes of buildings, public spaces, spatial organization, transport or even industrial activities. So, adaptive strategies could be possible in different ways.

The main consequence of the UHI could be a lack of comfort due to possible heat wave intensification (Rosenzweig et al., 2005). This happened during the 2003 summer in lots of European countries, in particular, in France during two weeks in average. All microclimatic phenomena as heating retention, evapotranspiration reduction or heating emission due to human activities would be affected and would be intensified which could lead to a stronger lack of comfort for urban citizens (Colombert, 2008). The way of life of people could change. For instance, one can imagine that people would have to stay home most of the time during the day in summer, which would imply changing of plans during the day and having the main activity during evenings or nights for instance. In that case, economic consequences could happen as well. People working outside and exposed to heat could see a decrease of their activities or, even worse, might have to stop working. However, people could adapt to this new situation and way of life during a warm season and have working conditions as in southern countries.

However, impacts to urban climate with respect to the countryside climate are not obvious, outside and inside comfort being a function of physical parameters and microclimatic locations, of people activity and their psychology. Brandt (2006) raised the question Does an "ideal" urban climate exist? Few scientists tackle the problem that way. They prefer to compare an urban climate to a rural one and propose some solutions for urban heat island effect reduction.

Another impact from an increase of heat waves concern health risks (IPCC, 2007). Health issues could be due to direct exposures to extreme climate events (physical impacts because of heat or psychological impacts because of an extreme event itself) or indirectly via air and water quality, mosquitoes, and so on (First Assessment Report of the Urban Climate Change Research Network, 2011; IPCC, 2007). In the case of hot weather, a lot of institutions advise people to stay home or to find shadow and a cool place for at least two hours during the hottest hours in the day. Numerical simulations of climate change show that heat waves, as in 2003, will not be an exception in the future. The frequency of occurrence in the increase of hot days in the future being very likely (IPCC, 2007; Desplat et al., 2009; Best and Betts, 2004). The climate in Paris could be the one in Cordoba from the second part of the 21st century (Hallegate et al., 2007). So, cooling systems, urban planning or buildings would have to be revised.

Heat waves and UHI effect have big consequences on people's health, in particular, older persons with respiratory disease (Rey et al., 2007). Indeed, urban climate slows down pollution dispersion and increases night temperatures. So, an increase of ozone and a lack of cooler temperatures during the night could lead to increase mortality of the popula- tion (Hallegate, 2007). Since this summer event in 2003 in France, hot day alert systems based on meteorological data have been created to warn people about risks (INVS, 2006), the goal being to detect hottest days coming if the temperature is above a certain threshold. However, this system is not perfect and would have to take into account an increase of temperature in the future, which could imply revising this threshold, alert system and prevention.

Risks coming from heat waves are double. Actual building standards are not adapted to support warm days longer than those during the heat wave in France in 2003 (Hallegate, 2007). In our latitudes about $44^{\circ}$, buildings are not built to support temperatures higher than $40^{\circ} \mathrm{C}$ for more than two weeks. If tomorrow Paris is at Cordoba's latitude, building standards have to be totally changed, apartments oriented in the South-West direction becoming too hot and less comfortable during summer. The comfort in habitations would get worse. So, one can predict a massive usage of cooling systems in apartments which would contribute to the urban heat island effect due to warm air exchanged with outside air in the atmosphere. Therefore, energy peak consumptions would increase drastically and energy production installation would have to support these power peaks.

The goal of this paper is then to study impacts of building and urban area vulnerabilities to climate change. It is indeed necessary to quantify existing and future vulnerabilities in order to anticipate future climate risks for improving urban resilience. Data and methodology involving multi-climate datasets are first presented in Sect. 2. Climate data is obtained for the period 2050 to 2100 for two climate scenarios A2 (the worst case carbon dioxide emission scenario) and B2 (moderate case) (IPCC, 2000) for 10 French cities. The potential evolutions of heating and cooling needs and comfort and health indicators are, thereafter, obtained for each city in Sect. 3 to analyse climate risks in urban environment. The vulnerabilities and impacts on comfort, health and energy are then discussed in Sect. 4.

\section{Data and methodology}

The first part of this study consists of calculating the desired hourly climate data from 2050 to 2100 . To do so, data from the Swiss software Meteonorm are used as meteorological basis in the calculi. They are supposed to be calculated and representative of the period 1996-2005 and have an hourly time-scale.

Data from the French Meteorological Agency, MétéoFrance, are also used as inputs. They result from a climate change simulator which computes daily climate simulations for the 2050-2100 period according to the scenarios B2 (moderate) and A2 (worse case) from the IPCC Special Report of Emissions Scenarios (2000). Interpolations between Meteonorm and Météo-France datasets (methodology 
presented hereafter) are then carried out in order to create data on an hourly time-scale basis for the period 2050-2100.

\subsection{Météo-France data}

In their study, the Intergovernmental Panel on Climate Change (IPCC) predicts a global mean temperature increase between $1.1^{\circ} \mathrm{C}$ and $6.4^{\circ} \mathrm{C}$ before the end of this century, which could change the radiative equilibrium of the Earth. These predictions are based on several carbon dioxide emission scenarios going from the moderate one (B2) to the worst case scenario A2 (IPCC, 2000).

In our study, climate data are obtained from the climate change simulator realised by the French Meteorological Agency (http://climat.meteofrance.com/chgt_climat/ simulateur/interpretation). This simulator simulates daily climate consequences in France for the period 2050-2100 for the two different scenarios B2 and A2 by means of the ARPEGE-Climat model developed by this agency with a spatial resolution of about $40 \mathrm{~km}$. The use of this simulator allows us to get a possible estimation of a future climate, despite uncertainties of model and chaotic behaviour of the climate system evolution. The uncertainties considered here are the range of temperature changes in 2100 produced by IPCC models: $\pm 0.7{ }^{\circ} \mathrm{C}$ for the scenario $\mathrm{B} 2$ and $\pm 1{ }^{\circ} \mathrm{C}$ for the scenario $\mathrm{A} 2$. We can note that only the tendency of climate parameter evolution needs to be considered and not a specific result for a specific day, season or year.

The climate simulator computes the minimum and maximum temperatures at $2 \mathrm{~m}$, the global horizontal radiation, the precipitation and the relative humidity for both scenarios for the period 2050-2100 in France. For our study, minimum and maximum daily temperatures are obtained from this simulator for $\mathrm{B} 2$ and $\mathrm{A} 2$ scenarios for 10 French cities: Paris, Orléans, Mante-la-Jolie, Nantes, Bordeaux, Toulouse, Clermont-Ferrand, Marseille, Besançon and Strasbourg. The choice of these cities is first based on pilot cities chosen in the French Resilis project (Paris, Orléans and Mante-la-Jolie) because of flooding and urban heat island risks and secondly on their location having a different climate behaviour. Locations of cities are shown on Fig. 1.

\subsection{Meteonorm data}

The global climate database Meteonorm (www.meteonorm.com) is primarily a method for the calculation of solar radiation on arbitrarily building orientated surfaces at any desired location. The method is based on databases and algorithms coupled according to a predetermined scheme. It commences with the user specifying a particular location for which meteorological data are required, and terminates with the delivery of data of the desired structure and in the required format.

The database was initiated by the Swiss Federal Office of Energy in 1985. Since 2010 the version 6.1 is available. Me-

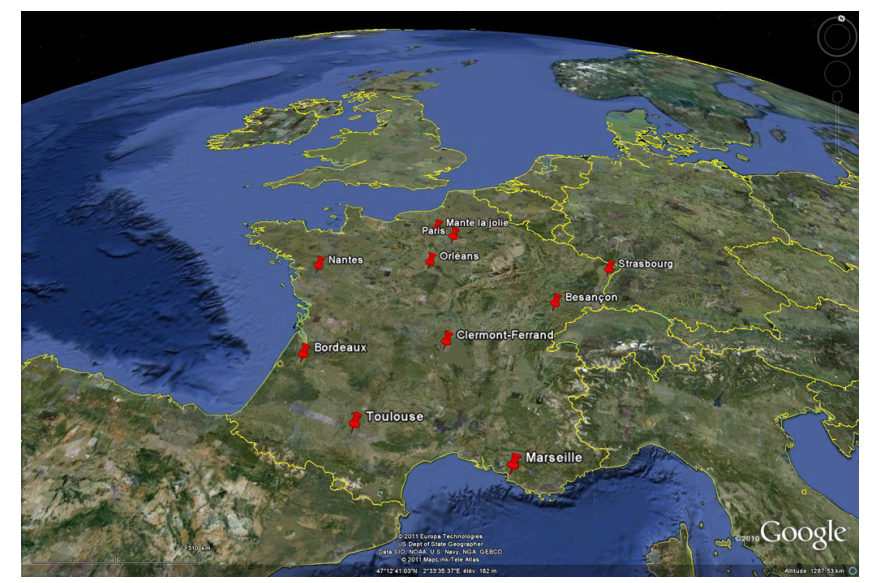

Fig. 1. Locations of the 10 French cities on Google Earth.

teonorm software delivers radiation parameters on horizontal and inclined planes. Aside from this, many other meteorological parameters like temperature, dew point temperature or wind speed are included. The values can be obtained in the form of monthly and yearly long-term means, as well as stochastically generated time series in hourly and minute time resolution, which correspond to typical years.

The main source of global radiation is the Global Energy Balance Archive (GEBA) of the ETH Zurich. The main source of all other parameters is the World Meteorological Organization (WMO) climate normals from 1961-1990 (WMO, 1998). Descriptions of the chain of algorithms can be found in Remund et al. (1998), Remund and Kunz (2003), Remund et al. (2007) or Badescu (2008).

Depending on specific user requirements, the user must choose the most suitable method from among the numerous procedures available in Meteonorm. A whole series of dependent parameters in addition to the measured data are available. In choosing the data, the quality and relevance of the basis datasets must be considered:

- Measured and interpolated monthly values are of similar precision. Although measured data reflect the specific characteristics of a local site, they are always subject to measurement errors, and these tend to be compensated by the interpolation process. Interpolated data should, therefore, be used at sites with no weather station in the vicinity (approx. $20 \mathrm{~km}$ distance).

- Dependent parameters such as diffuse radiation, celestial radiation, dew point temperature, etc., which are determined from calculated as opposed to measured data, are subject to greater inaccuracy owing to error propagation.

Certain inconsistencies could not be avoided then. However, it is always possible to establish which data basis and algorithms were used. Differences between the various databases and algorithms may be summarized as follows: 
- The radiation data was subjected to extensive tests. The error in interpolating the monthly radiation values was $9 \%$ and for temperature $1.5^{\circ} \mathrm{C}$. The Meteonorm radiation database is based on 20-yr measurement periods, the other parameters mainly on 1961-1990 and 19962005 means. Comparisons with longer term measurements show that the discrepancy in the average total radiation, due to choice of time period, is less than $2 \%$ for all weather stations.

- In general, the hourly model tends to overestimate slightly the total radiation on inclined surfaces by 0 $3 \%$ (depending on model). The discrepancy compared to measured values is $\pm 10 \%$ for individual months and $\pm 6 \%$ for yearly sums.

In order to build hourly temperature data from daily temperature data obtained by Météo-France (methodology discussed in the next section), hourly temperature data are generated for the same 10 cities from the database Meteonorm for the averaged period 1996-2005 (Remund, 2007). An interpolation of Météo-france daily temperature data is then realised on Meteonorm hourly temperature data. The principle is explained in the following section.

\subsection{Interpolation principle for hourly temperature data}

The goal of this methodology is to get hourly temperature data for the period 2050-2100 from existing climate data. So, Météo-France data are interpolated based on data such as:

- daily minimum and maximum Meteonorm data are calculated;

- use of an interpolation function for each day $j$ makes the assumption that hourly evolution during the day in a future climate will be sensibly the same than today. Therefore, minimum, maximum and mean temperature tendencies evolve more than hourly temperature evolution itself.

- hourly Météo-France data are computed for the period 2050-2100 based on daily minima and maxima (Fig. 2).

Knowing the hourly temperature evolution $f_{j}(t)$ for the day $j$, with a daily minimum and maximum $a_{j}$ and $b_{j}$, respectively, from Meteonorm data, the daily temperature evolution for a future climate $F_{j}(t)$ can be interpolated via an empirical function such as:

$\forall j \in[1 ; 365], F_{j}(t)=\frac{\beta_{j}-\alpha_{j}}{b_{j}-a_{j}} f_{j}(t)+K_{j}$

where $\alpha_{j}$ and $\beta_{j}$ are, respectively, the minimum and the maximum of temperature given by Météo-France data, and $K_{j}$ is a constant given by:

$K_{j}=-\frac{\beta_{j}-\alpha_{j}}{b_{j}-a_{j}} a_{j}+\alpha_{j}$

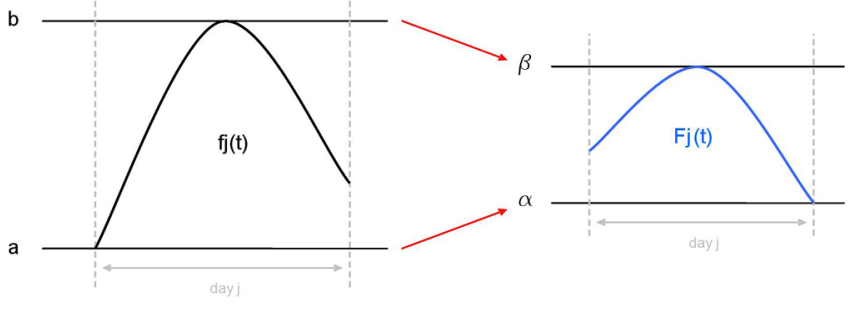

Fig. 2. Interpolation principle.

This function allows us to get hourly data for the period 2050-2100. The continuity over the year is verified since each function $f_{j}(t)$ is continuous (Lang, 1997).

\subsection{Unified Degree Day}

According to the French Meteorology Agency, the Unified Degree Day (UDD) is representative of annually heating and cooling energy needs. The degree day is taken here as the difference between an outside temperature at a specific hour $T_{\text {out }}$ during the day and an inside temperature. The unified degree day is based on a temperature of reference $T_{\text {ref }}$ taken inside the building. Two different temperatures of reference $T_{\text {ref }}$ are considered as a function of the heating and cooling period (U.R.E, 1999) in order to get annually UDD from hourly climate data for the period 2050-2100:

- For the heating period (from the 1 October to the 20 May): $T_{\text {ref }}=18^{\circ} \mathrm{C}$.

- For the cooling period (the entire year): $T_{\text {ref }}=25^{\circ} \mathrm{C}$

In France, these temperatures of reference are classical values to estimate energy needs for building (U.R.E., 1999).

Considering the number of heating hours (NHH) during a day when $T_{\text {out }} \leq T_{\text {ref }}$, and the number of cooling hours (NHC) during a day when $T_{\text {out }} \geq T_{\text {ref }}$, heating and cooling UDDs are then given by:

$\begin{cases}\mathrm{UDD}_{\text {heat }}=\frac{1}{\mathrm{NHH}} \sum_{i=0}^{\mathrm{NHH}}\left(T_{\mathrm{ref}}-T_{\mathrm{out}_{i}}\right), & \text { for } T_{\mathrm{out}} \leq T_{\mathrm{ref}} \\ \mathrm{UDD}_{\mathrm{cool}}=\frac{1}{\mathrm{NHC}} \sum_{i=0}^{\mathrm{NHC}}\left(T_{\mathrm{out}_{i}}-T_{\mathrm{ref}}\right), & \text { for } T_{\mathrm{out}} \geq T_{\mathrm{ref}}\end{cases}$

Using $T_{\text {ref }}=18{ }^{\circ} \mathrm{C}$ and $T_{\text {ref }}=25^{\circ} \mathrm{C}$ for the heating and cooling periods, respectively, Eq. (3) becomes:

$\begin{cases}\text { UDD18 }=\frac{1}{\mathrm{NHH}} \sum_{i=0}^{\mathrm{NHH}}\left(18-T_{\text {out }_{i}}\right), & \text { for } T_{\text {out }} \leq 18^{\circ} \mathrm{C} \\ \mathrm{UDD} 25=\frac{1}{\mathrm{NHC}} \sum_{i=0}^{\mathrm{NHC}}\left(T_{\text {out }_{i}}-25\right), & \text { for } T_{\text {out }} \geq 25^{\circ} \mathrm{C}\end{cases}$

The total annually UDD is obtained by summing the daily UDDs over the heating and cooling periods for every year between 2050 and 2100 . 


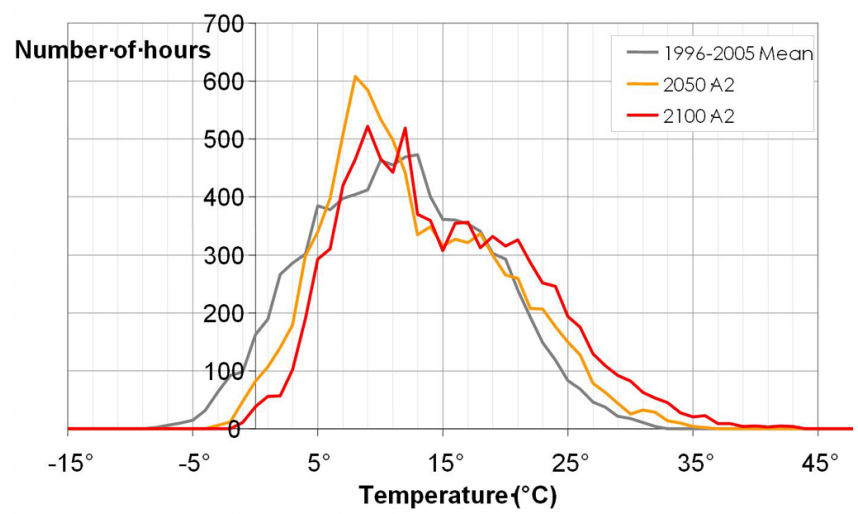

Fig. 3. Annual distribution of the number of hours for the temperature for Paris in the case of the scenario A2.

\section{Climate indicators}

City shapes impact on local climate. What would the city's vulnerability be to face the climate change then? What kind of information could be useful to mitigate risks and make easier urban resilience? In order to analyse the impact of climate change on urban environment and to characterise vulnerability scenarios, four indicators are built:

- the number of hours when the temperature is above $28^{\circ} \mathrm{C}(\mathrm{NHT} 28)$;

- the heating UDD (UDD18);

- the cooling UDD (UDD25);

- the cross-energetic indicator.

These indicators are climate-energy indicators: the first one allows us to estimate the evolution of heat waves in the future, while the cross-energetic indicator allows us to look at the evolution of energy needs in percentages.

\subsection{A case study: the city of Paris}

\subsubsection{Comfort and health indicator}

The number of hours when the temperature is above $28^{\circ} \mathrm{C}$ (NHT28) relates to energy outside urban comfort and urban climate, but also can anticipate an impact on health. Within the context of climate change, the tendency of NHT28 should increase. Figure 3 shows, for instance, the distribution of the number of hours for the temperature evolving between $-15^{\circ} \mathrm{C}$ and $45^{\circ} \mathrm{C}$ for both the years 2050 and 2100 for the worst case scenario A2 in Paris, compared to the averaged period 1996-2005. In general, the annually mean temperature would increase by $1.2{ }^{\circ} \mathrm{C}$ in 2050 in comparison with the averaged period $1996-2005$ going from $12.1{ }^{\circ} \mathrm{C}$ to $13.3^{\circ} \mathrm{C}$. This increase would be equal to $3.4^{\circ} \mathrm{C}$ in 2100 given an annual mean temperature of about $15.5^{\circ} \mathrm{C}$. Moreover, NHT28

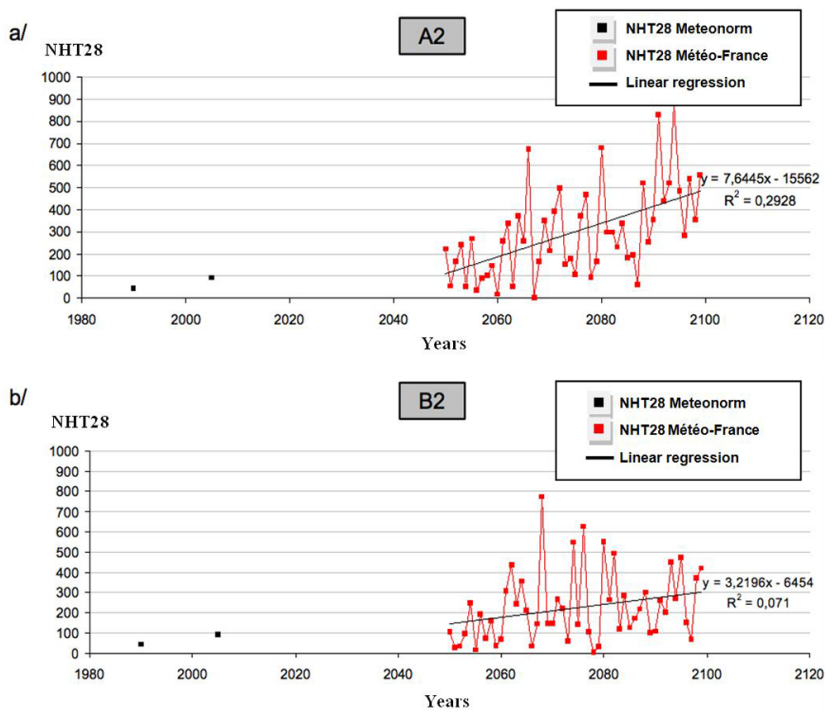

Fig. 4. Number of hours when $T>28^{\circ} \mathrm{C}$ for the scenarios A2 (a) and B2 (b), in Paris.

would increase to about more than $300 \%$ in 2100 , going from $30 \mathrm{~h}$ for the period $1996-2005$ to $120 \mathrm{~h}$ in 2100 . Therefore, these results clearly show an increase in temperature on average in the city and are in favour of a climate change.

This increase is also well shown in Fig. 4 when looking at NHT28 for the period 2050-2100 for both scenarios. Indeed, a significant increase of NHT28 during these $50 \mathrm{yr}$ is obtained for the scenario A2 (Fig. 4a). The slope coefficient of the linear regression calculated for the period 2050-2100 is above 7.5. Moreover, the variability of this tendency is important as emphasized by the correlation coefficient which is less than 0.3. Noting that the calculated mean NHT28 follows the linear regression (not shown), the variability of NHT28 can double in some years in comparison with the mean, reaching a peak close to 900 , while NHT28 is divided by two the year after, getting back close to the mean value. The same kind of tendency is obtained for the scenario B2 (Fig. 4b) but moderate, showing an increase of NHT28 of about $200 \%$ between 2050 and 2100 .

Averaging NHT28 from the two Meteonorm climate databases for the periods 1960-1990 and 1996-2005, NHT28 is equal to 67 , while the NHT28 average from Météo-France climate data for the period 2050-2100 is equal to 296 for the scenario A2 and 225 for the scenario B2. So, we can see an increase of about $341 \%$ (235\%) for the worst case scenario A2 (B2) in Paris between the period 19602005 and the period 2050-2100. These results show that even for the moderate scenario B2, the increase of the number of hours when $T>28^{\circ} \mathrm{C}$ would be very consequential and important during the 21 st century. This could imply different consequences that will be discussed later. 


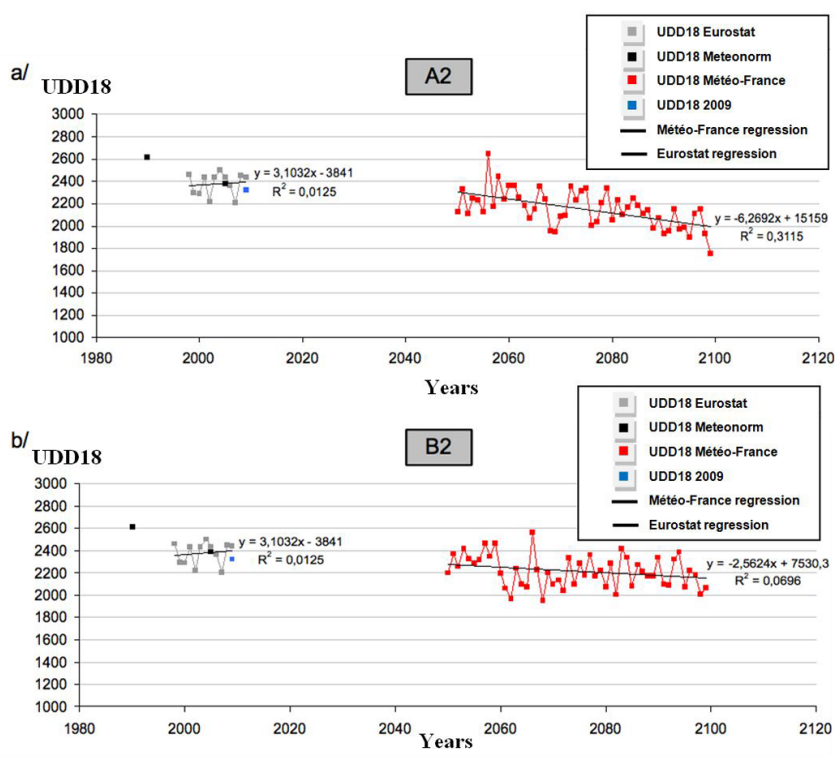

Fig. 5. Heating UDD for the scenario A2 (a) and B2 (b) in Paris.

\subsubsection{Heating UDD}

As NHT28, the tendency of UDD18 is observed for fifty years between 2050 and 2100 and is compared to observations from the past climate (Fig. 5). In that case, Eurostat data coming from a European statistic database (Eurostat, 2010) is also used to look at the evolution of UDD18 for the period 1998-2009, Meteonorm data being still used as a reference. The linear regression calculated for the period 2050-2100 shows a clear decrease in the future for both scenarios, while a slight increase is observed today when looking at Eurostat data. For the scenario B2, UDD18 decrease is slightly less than in the scenario A2. This shows the impact of the climate scenario. On average over the period 2050-2100, the decrease is about $13 \%$ in the worst case scenario and about $5 \%$ for the scenario $\mathrm{B} 2$.

In these results, the observed variability could come from different kinds of uncertainties due to input data, modelling or computation (IDDRI, 2010):

1. uncertainties due to climate scenarios;

2. uncertainties due to modelling (cloud formation, climate feedback, etc...);

3. uncertainties due to the intrinsic natural climate variability which is a chaotic phenomenon (El Nino for instance);

4. uncertainties due to the temporal and spatial downscaling.

\subsubsection{Cooling UDD}

The principle is the same here as for heating. The temperature of reference is equal to $25^{\circ} \mathrm{C}$ inside buildings. So, every

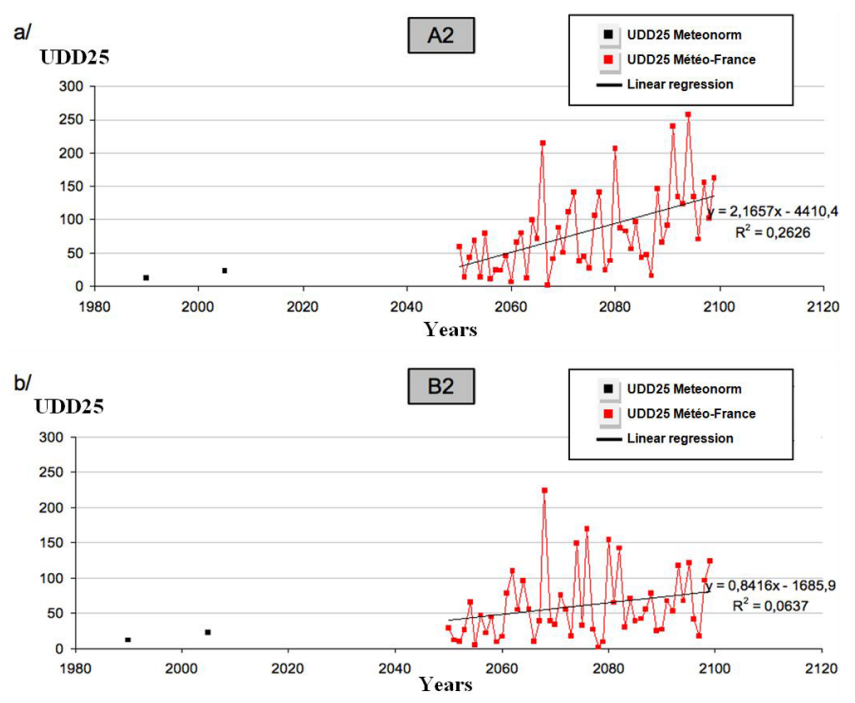

Fig. 6. Cooling UDD for the scenario A2 (a) and B2 (b) in Paris.

temperature outside above this temperature of reference implies energy needs for cooling. So, we can expect that cooling needs would increase in the context of climate change in the city, in particular because of the increase of the number of hours when the temperature is above $28^{\circ} \mathrm{C}$ and the increase of heat waves in the future. As for heating, results from Météo-France for the period 2050-2100 are compared to the observations coming from Meteonorm for the past climate. Figure 6 shows UDD25 for both climate scenarios A2 and B2. On average, UDD25 goes from 18 (average over the two Meteonorm databases) to 82 (average over the period 2050-2100 of Météo-France data for the scenario A2). As a consequence, cooling needs would blow up with an increase of about $355 \%$ (230\%) for the scenario A2 (B2) between 2050 and 2100 . So, these needs would increase at least by a factor of 3 despite the moderate climate scenario.

\subsection{Geographical influence}

The tendencies of these three indicators described previously are calculated for nine other French cities to look at the geographical influence over the country. Figure 7 shows these climate indicators for all the 10 cities. Each indicator value corresponds to an average value obtained for the period 2050-2100 in the case of future climate Météo-France data. For observational data, the value is averaged between the two databases (1960-1990 and 1996-2005) for Meteonorm and for the period 1996-2005 for Eurostat data. Averaged values are summarized in the Table 1.

For NHT28 and UDD25, their tendencies are clearly correlated $\left(R^{2}>0.97\right)$. For all cities, these indicators show an increasing tendency. The strongest NHT28 and UDD25 increase occurs for the city of Nantes in the west part of France, which reaches a value of about $770 \%$ for both indicators for scenario A2, followed by Toulouse with an increase in 
Table 1. NHT28, UDD18 and UDD25 averaged values for 10 French cities for observational data and climate data from the period 20502100 for the scenarios A2 and B2.

\begin{tabular}{|c|c|c|c|c|c|c|c|c|c|}
\hline \multirow[b]{2}{*}{ Cities } & \multicolumn{3}{|c|}{ NHT28 } & \multicolumn{3}{|c|}{ UDD18 } & \multicolumn{3}{|c|}{ UDD25 } \\
\hline & MNRM & A2 & B2 & Eurostat & A2 & B2 & MNRM & A2 & $\mathrm{B} 2$ \\
\hline Besançon & 74 & 348 & 249 & 2788 & 2484 & 2556 & 20 & 103 & 70 \\
\hline Bordeaux & 126 & 705 & 582 & 1853 & 1642 & 1722 & 32 & 215 & 172 \\
\hline Clermont-Ferrand & 61 & 357 & 247 & 2891 & 2679 & 2768 & 15 & 105 & 69 \\
\hline Mantes la Jolie & 60 & 200 & 134 & 2376 & 2278 & 2337 & 16 & 54 & 35 \\
\hline Marseille & 278 & 970 & 826 & 2192 & 1777 & 1869 & 67 & 271 & 218 \\
\hline Nantes & 50 & 434 & 324 & 2117 & 1717 & 1779 & 14 & 121 & 87 \\
\hline Orléans & 85 & 400 & 299 & 2336 & 2098 & 2166 & 22 & 112 & 82 \\
\hline Paris & 67 & 296 & 225 & 2376 & 2153 & 2215 & 18 & 82 & 60 \\
\hline Strasbourg & 61 & 189 & 117 & 2637 & 2702 & 2759 & 18 & 55 & 33 \\
\hline Toulouse & 158 & 1066 & 878 & 2156 & 1723 & 1814 & 44 & 343 & 270 \\
\hline
\end{tabular}
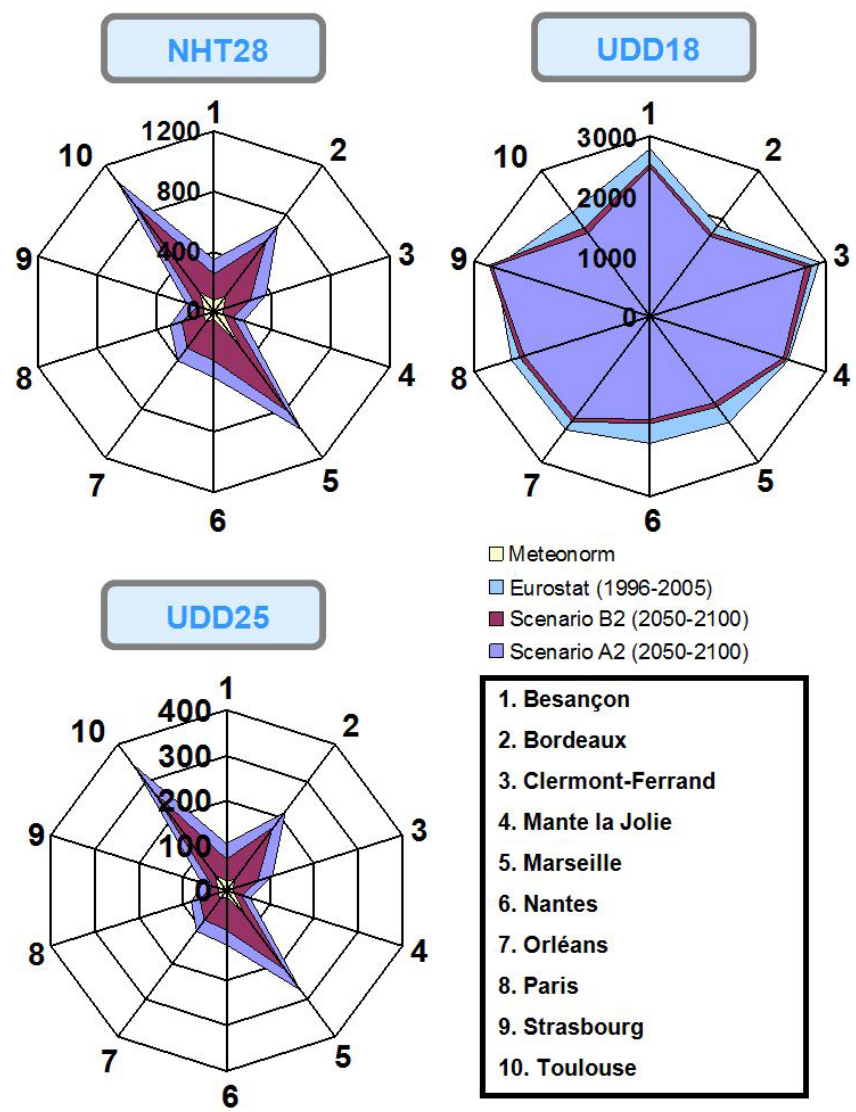

$\square$ Meteonorm

$\square$ Eurostat (1996-2005

$\square$ Scenario B2 (2050-2100)

$\square$ Scenario A2 (2050-2100)

\begin{tabular}{|l|}
\hline 1. Besançon \\
2. Bordeaux \\
3. Clermont-Ferrand \\
4. Mante la Jolie \\
5. Marseille \\
6. Nantes \\
7. Orléans \\
8. Paris \\
9. Strasbourg \\
10. Toulouse \\
\hline
\end{tabular}

Fig. 7. NHT28, UDD18 and UDD25 mean values for 10 French cities for the scenarios A2 and B2.

the number of hours when the temperature is above $28^{\circ} \mathrm{C}$ of about $575 \%$. Strasbourg has the lowest value with still an increase of $210 \%$ for NHT28, slightly more for UDD25 with an increase of $215 \%$. In general, tendencies for scenario B2 is equivalent, but smaller than for the worst case scenario.
In general, UDD18 decreases in all cities except in Strasbourg where UDD18 increases a little bit by $5 \%$ for the scenario B2 and about $2 \%$ for the case A2. Moreover, UDD18 for cities in the south of France is globally going down with the strongest decreases which could be directly linked to a more pronounced global warming in these regions. Indeed, Nantes, Toulouse or Marseille show an UDD18 decrease of about $20 \%$ for in the worst case scenario A2 for instance. Globally, energy needs for heating would decrease in France during the 21st century.

\subsubsection{Cross-energetic indicator}

The evolution of these energetic indicators is correlated with climate change. The comfort indicator, NHT28, shows clearly an increase in the number of hours when the temperature is above $28^{\circ} \mathrm{C}$, whatever the city, as well as an increase of heat waves (not shown). So energy needs would have to evolve in the future considering this increase in cooling needs.

However, indicator values are dependent of the climate model which is ARPEGE-Climat from Météo-France. So, another way to observe the tendency of these indicators is to look at the evolution of energy needs in percentage between the periods 1996-2005 and 2050-2100 as a function of the climate scenario. Figure 8 shows this evolution for each heating and cooling needs, while the evolution of NHT28 corresponds to the diameter of bubbles. This one is equal to $50 \%$ for a bubble equivalent to the legend which never occurs. It is interesting to see for Nantes, for instance, that cooling needs would increase by about $780 \%$ when heating needs would decrease by about $19 \%$.

Globally, the energy policy will have to take into account these needs in the future and diversify available energies for cooling needs. In the case of Strasbourg, we can note that this is the only city where UDD18 is positive about 3 to $5 \%$ depending of the climate scenario. Since this city is more on the East part of France, the continental climate would stay 
A/ Scenario A2: Heating vs Cooling UDD Evolution (\%)

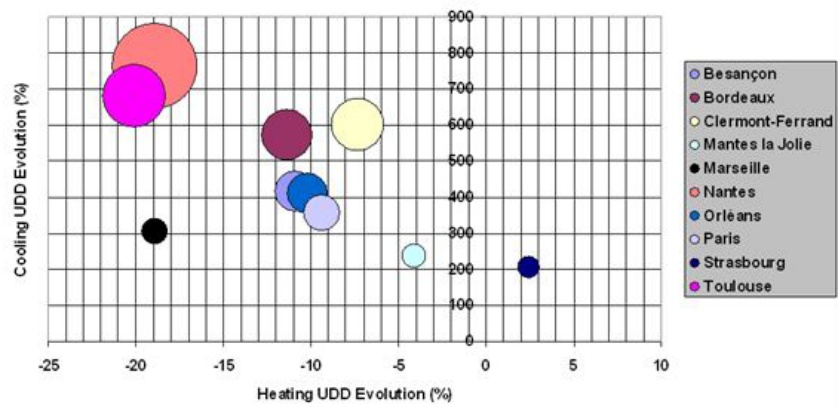

B/ Scenario B2: Heating vs Cooling UDD Evolution (\%)

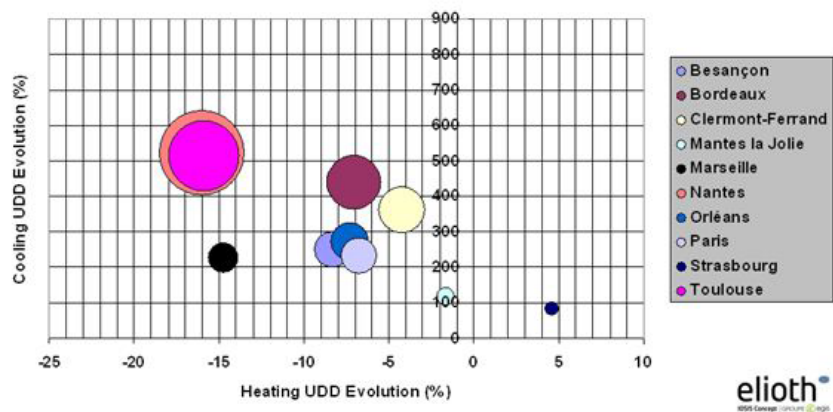

Fig. 8. Evolution of heating and cooling needs (Unified Degree Day or UDD) from 1996-2005 to 2050-2100 periods (Bubble diameters function of the evolution of number of hours where temperature is above $28{ }^{\circ} \mathrm{C}:+50 \%$ in the legend). (A) Scenario A2, (B) Scenario B2.

quite cold during the winter having extreme weathers sometimes, despite the global warming, which could explain this tendency.

\section{Discussion}

Due to the global warming, UDD18 tends to decrease while UDD25 and NHT28 tend to increase. These tendencies are accentuated for the worse case climate scenario A2. A decrease of UDD18 could prevent a decrease in heating needs and consumptions. The more the outside temperature is high, the more UDD18 is low and the less necessary it is to heat a building. The global warming should logically imply less energy consumption for heating in mid-latitudes. However, these evolutions are tendencies and the climate variability is still present every year.

On the opposite side, the more NHT28 is increasing, the more UDD25 is expected to increase as well. Potential impacts could be urban heat island effect intensification, comfort and health risk increase and more energy needs for cooling. These vulnerabilities can be classified into two vulnerability models (Fig. 9), the functional and the bio-physical vulnerability models (Arnaud, 2011), showing possible im-

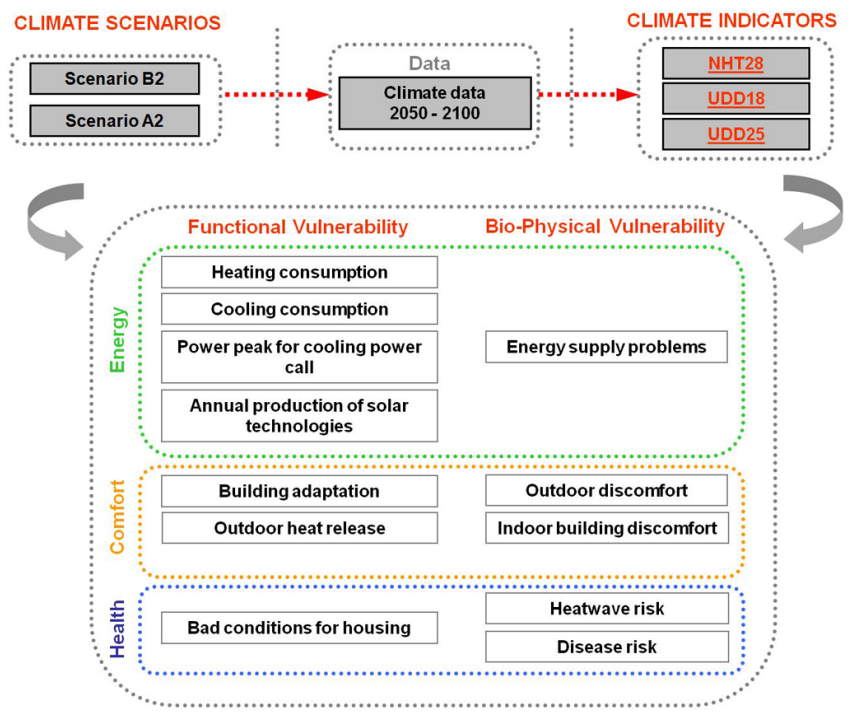

Fig. 9. Vulnerability models and impacts on energy, comfort and health.

pacts on energy, comfort and health. Our climate indicators allow us to put forward working or malfunction issues related to urban climate. For instance, industrial sectors and services in France would be more concerned about energy needs to cool buildings, since just a few apartments have cooling systems. Although these indicators are independently studied and presented, they are all connected. For instance, UDD25 and NHT28 have the same tendency, data for a temperature above $28^{\circ} \mathrm{C}$ being taking into account for both indicators. Moreover, in general, if more cooling is needed, this implies less heating in buildings.

New environmental building conception tries to avoid cooling systems since this implies more energy consumptions. So, either a massive reform of environmental conceptions and building standards would be necessary (Roaf et al., 2005) or a massive installation of cooling systems would have to be done. There will be a price to pay: price of energy or a new vision of building conception. Hallegatte (2007) raised a fundamental question when he asked if population will accept the use of cooling systems everywhere in Paris as in big cities in the USA. Of course, there will be an economic impact added to energy and carbon dioxide emission impacts which are the basis of the adaptation to climate change in urban areas. Answering this question is not so easy since urban climate studies are complex because of the multidisciplinary fields and actors.

Due to climate change, a frequency and intensity increase of extreme events would probably occur (IPCC, 2007). An increase of very cold winters would be possible and could influence peaks of energy demands and energy needs, and heating installations. The heating systems are designed from building energy losses and function by an extreme outside temperature of reference defined for each region in France, 
called base temperature, and equal to the lowest outside mean temperature in the year. For instance in Paris and its region, this base temperature is equal to $-7^{\circ} \mathrm{C}$. No data reaches this base temperature in the Météo-France data for the period 2050-2100. So, it would not be necessary to change heating systems already installed in Paris in the future which are well designed in the case of a global warming. But problems could come from extreme colds and a massive demand of energy for heating at the same time. So, heating systems are not questioned per say. This is more the network itself, the mean of energy production and distribution which are questioned, in particular, for electricity. A strong energy demand would imply a strong energy production. This situation could generate crisis situations difficult to manage.

As for heating demands, we could get the same problems during heat wave events with cooling systems. NHT28 and UDD25 tendencies show a strong vulnerability about the electricity network during hot days with a possible crash in the network depending on power peak limits and energy demands for cooling. Power peaks would happen mainly in the summer. But if demands are too strong, this could generate electricity production problems upstream in the network. Considering a hydraulic production, what would be the energy production if rivers drying out occur more frequently in the context of a global warming? Therefore, several adaptation scenarios can be imagined for cooling building in the future. The first one would consist of installing cooling systems in all old and new buildings. However, this extreme scenario is not recommended for environmental purposes $\left(\mathrm{CO}_{2}\right.$ emissions for instance) or building design, in particular, if cooling systems are installed on facades. Moreover, this solution would lead to the same power peak and demand problem during extreme hot events.

Another scenario would be to replace old cooling systems by new ones to get better installations in terms of energy consumptions. But the right technology has to be used. For instance, replacing cooling systems with humid air waste heat by dry air waste heat would increase the temperature by $2{ }^{\circ} \mathrm{C}$ in the city (CNRM-GAME, CNAM, Climespace, 2010). The use of air conditioners would then reinforce heat waste, increasing outside air temperature, which could heat buildings again, leading to a massive use of air conditioning, and so on. So, we have to pay attention to the choice of technology we want to use to adapt to climate change. In some cases, adaptable solutions could be worse than doing nothing. Moreover, the city itself can have a negative impact on cooling needs. The cities are very attractive and density is increasing. These continuous demographic increases tend to reinforce cooling needs during hot events. It is a vicious circle.

To break down this circle, several actions are possible to improve urban climate. However, how to evaluate the efficiency of these actions? What would be the evolution of the UHI phenomenon in the future? How to integrate new climatic criteria in the urban planning? What would be available tools for decision-makers to evaluate impacts of changes? The perspective of resilience within the context of climate change is then uncertain and difficult to do. Several levers of action for the UHI exist and are quite large, but all do not have the same efficiency. This one could vary during a day or as a function of a season (Colombert, 2008).

The main work will be to adapt current buildings, new ones representing only $1 \%$ to $1.5 \%$ of the French market. But communities and local authorities have to face a lot of legal constraints to plan and regulate space to improve urban climate. Besides, evaluation and quantification tools would be necessary to judge project qualities and urban resilience. The multiplicity of shapes in cities does not allow us to obtain a general answer or general law. For instance, UHI analysis in Paris showed that thermal anomaly is dependent of seasons or weather depressions in the region (Cantat, 2004), but mainly is due to radiation and wind speed (Bouyer, 2009). The use of morphological indicators as the sky view factor (Messaoud, 2009) or the aspect ratio is used to get empirical laws, but developed models cannot be reused as it is, in particular, for cities where climate is different (Bozonnet, 2006). If projections give a real increase in the lack of comfort in cities, it is possible to attenuate undesirable effects by changing some urban characteristics. It is, however, necessary to rethink city planning and to adapt this one in order to keep a pleasant way of life and comfortable activities in cities.

One possible lever of action is to modify building shapes and city's configurations. Height and width of buildings have to be thought over again to avoid canyon street formations where some radiation could get trapped and heat the air temperature. Acting on materials and their colour is another pathway to follow for modifying urban albedo, the reflective power of surfaces exposed to the light. The use of clear material (roofs and facades) would allow us to catch less heat which would be reflected towards the space and limit heating the city. So, the attenuation of UHI could be possible by increasing albedo of buildings (Akbari et al., 2001, 2009; Gaffin, 2012). Despite this solution for cooling a city, this cannot avoid extreme hot events as predicted in climate scenarios and lack of comfort in public space.

To improve this public comfort, shapes, aspects or geometry of public roads could be modified to increase albedo. Moreover, the increase of green roofs, vegetal facades or parks could limit heating a city as well. This green revolution could attenuate UHI and would offer shadows and relaxation spaces. Desplat et al. (2009) show that albedo and green surfaces are the two main levers which could contribute to cooling a city and reducing urban heat island effect. In their study, they put forward that these solutions would reduce the mean air temperature of a city by $2{ }^{\circ} \mathrm{C}$ and then attenuate the lack of comfort by the horizon 2030 .

Of course, people have a role to play in this adaptation by limiting air pollution, traffic or industrial activities. During heat waves, atmospheric pollution is intensified and increase the lack of comfort and health risks by the time. Possible 
solutions would be to move polluting activities outside the city, reduce car traffic and allow more space for bikers or buses to avoid traffic jams and peak pollution, in particular, during rush hour. So, spatial city organization would have to be rethought like city density (building density, human density, green density, etc.) or green space location in cities. Again, all these solutions call city planners, architects or policy makers to adapt a city planning face to the global warming. The single fact that urban heat island effect would be increased because of the global warming and possible negative consequences on people would happen, should lead actors to think cities differently by proposing adaptive strategies. This suggests a reframing of the traditional role of climate on a building in the architectural field to be reversed and look at the role of the building on local climate. The resilience to climate change will then be possible with an adaptive design, but with an adaptive consciences as well.

Acknowledgements. The authors address their thanks to the Resilis partners. Resilis gathers researchers from the private sector (Egis, Iosis, Sogreah) involved in urban development or risk prevention, research laboratories (EIVP - Paris School of Engineering, LEESU - University of Marne-la-Vallée department of research in urban engineering, REEDS - University of Versailles-Saint Quentin department of research in economy, ecology and sustainable development), public research (Cemagref - risk assessment, Fondaterra - foundation for sustainable territories). This complementariness in skills and knowledge will ensure the more holistic approach possible with the analysis of both technico-functionnal and socio-organizational resilience.

Edited by: B. Barroca

Reviewed by: M. Colombert and another anonymous referee

\section{References}

Akbari, A., Pomerantz, M. and Taha, H.: Cool surfaces and shade trees to reduce energy use and improve air quality in urban areas, Sol. Energy, 70, 295-310, 2001.

Akbari, H., Menon, S., and Rosenfeld, A.: Global cooling worldwide urban albedos to offset $\mathrm{CO}_{2}$, Climatic Change, 94, 275286, doi:10.1007/s10584-008-9515-9, 2009.

Arnaud, J. P., Toubin, M., and Serre D.: RESILIS: a research project to improve urban resilience, EGU, Vienna, Austria, 3-8 April 2011.

Badescu, V. (Ed.): Modeling Solar Radiation at the Earth's Surface, Springer-Verlag, Berlin, Heidelberg, 2008.

Best, M. and Betts, R.: The impact of climate change on our cities, The impact of climate change on our cities, 2004.

Brandt, K: Does an "IDEAL" Urban Climate Exist?, 6th International conference on Urban Climate, 443-445, 2006.

Bouyer, J.: Modélisation et simulation des microclimats urbains étude de l'impact de l'aménagement urbain sur les consommations énergétiques des bâtiments, $\mathrm{PhD}$ thesis, Ecole polytechnique de l'Université de Nantes, 2009.

Bozonnet, E.: les microclimats urbains et la demande énergétique du bâti, XXIVe Rencontres Universitaires de Génie Civil, 2006.
Cantat, O.: L'îlot de chaleur urbain parisien selon les types de temps, Norois, 191, 75-102, 2004.

CNRM-GAME, CNAM, Climespace: CLIM2 French project, urban climate and air conditioning, scientific report, November 2010.

Colombert, M.: Contribution à l'analyse de la prise en compte du climat urbain dans les différents moyens d'intervention sur la ville, $\mathrm{PhD}$ thesis, University of Marne la Vallée, 2008.

Desplat, J., Lauffenburger, M., Salagnac, J. L., Kounkou-Arnaud, R., Lemonsu, A., Colombert, M., and Masson, V.: Projet EPICEA, étude pluridisciplinaire des impacts du changement climatique à l'échelle de l'agglomération, Fifth Urban Research Symposium, 2009.

Eurostat: Statistiques de l'énergie - degrés-jour de chauffage, available at: http://epp.eurostat.ec.europa.eu/portal/page/portal/ energy/data/database, 2010.

First Assessment Report of the Urban Climate Change Research Network: Climate Change and Cities, edited by: Rosenzweig, C., Solecki, W. D., Hammer, S. A. and Mehrotra, S., 312 pp., April 2011.

Gaffin, S. R., Imhoff, M., Rosenzweig, C., Khanbilvardi, R., Pasqualini, A., Kong, A. Y. Y., Grillo, D., Freed, A., Hillel, D., and Hartung, E.: Bright is the new black - multi-year performance of high-albedo roofs in an urban climate, Environ. Res. Lett., 7, 014029, doi:10.1088/1748-9326/7/1/014029, 2012.

IDDRI (Institut du Développement Durable et des Relations Internationales): INVULNERABLe project, http://www.iddri.org/L' iddri/Fondation/Projet-INVULNERABLe, 2010.

INVS, Rapport Annuel available at: http://archives. invs.sante.fr/publications/2007/rapport_annuel_2006/

rapport_annuel_invs_2006.pdf (last access date 04/25/2012), 2006 .

IPCC: Special Report on Emissions Scenarios, 2000.

IPCC Fourth Assessment Report: Climate Change, (AR4), 2007.

Hallegatte, S., Hourcade, J.-C., and Ambrosi, P.: Using Climate Analogues for Assessing Climate Change Economic Impacts in Urban Areas, Climate Change, 82, 47-60, doi:10.1007/s10584006-9161-z, 2007.

Hallegatte, S.: Accepterons-nous un Paris climatisé à l'américaine?, Interview, La Libération, newspaper, 2007.

Lang, S.: Undergraduate analysis, Undergraduate Texts in Mathematics (2nd Edn.), Berlin, New York: Springer-Verlag, ISBN 978-0-387-94841-6, section II.4, 1997.

Lhomme, S., Serre, D., Diab, Y., and Lagagnier, R.: Les réseaux techniques face aux inondations ou comment définir des indicateurs de performances de ces réseaux pour évaluer la résilience urbaine, Bulletin de l'association des géographes français, 487502, 2010.

Messaoud, B.: Approche physico-morphologique de l'albédo effectif, Master thesis, Ecole Supérieure d'Architecture de Nantes, 2009.

Météo France: Unified Degree Day definition: available at: http: //climatheque.meteo.fr/Docs/DJC-methode.pdf, 2005.

Remund, J. and Kunz, S.: The new version of the worldwide climatological database METEONORM, Proceedings of the ISES solar world congress 2003, Göteborg Sweden, CD-ROM Paper P6 39, 2003.

Remund, J., Salvisberg, E., and Kunz, S.: Generation of hourly shortwave radiation data on tilted surfaces at any desired loca- 
tion, Sol. Energy, 62, 331-334, 1998.

Remund, J., Kunz, S., and Schilter, C.: Handbook of METEONORM Version 6.0, Part II: theory, Meteotest, Fabrikstrasse 14, 3012, Bern, Switzerland, 2007.

Rey, G., Jougla, E., Fouillet, A., Pavillon, G., Bessemoulin, P., Frayssinet, P., Clavel, J., and Hémon, D.: The impact of major heat waves on all-cause and cause-specific mortality in France from 1971 to 2003, Int. Arch. Occup. Environ. Health, 80, 615626, 2007.
Roaf, S., Crichton, D., and Fergus, N.: Adapting buildings and cities for climate change, a 21st century survival guide, Elsevier, 363 pp., 2005.

Rosenzweig, C., Solecki, W. D., Parshall, L., Chopping, M., Pope, G., and Goldberg, R.: Characterizing the urban heat island in current and future climates in New-Jersey, Environ. Hazards, no. 6, 51-62, 2005.

U.R.E Bâtiment: Guide d'Audit Energétique 1999, Ed. Ademe \& COSTIC, 1999. 